\title{
Changes in Pediatric Fracture Cases during the Coronavirus Disease 2019 Pandemic: Data from a National Referral Orthopedic Hospital in Indonesia
}

\author{
Pamudji Utomo $^{1,2 *}$ (D), Muhammad Yogatama Wirawan², Hendra Cahya Kumara ${ }^{1,2}$ D , Mochamadsyah Beizar Yudistira ${ }^{2}$ (D) \\ ${ }^{1}$ Department of Orthopedic and Traumatology, Faculty of Medicine, Universitas Sebelas Maret, Prof. Dr. R. Soeharso \\ Orthopedic Hospital, Surakarta, Indonesia; ${ }^{2}$ Department of Orthopedic and Traumatology, Prof Dr. R. Soeharso Orthopedic \\ Hospital, Surakarta, Indonesia
}

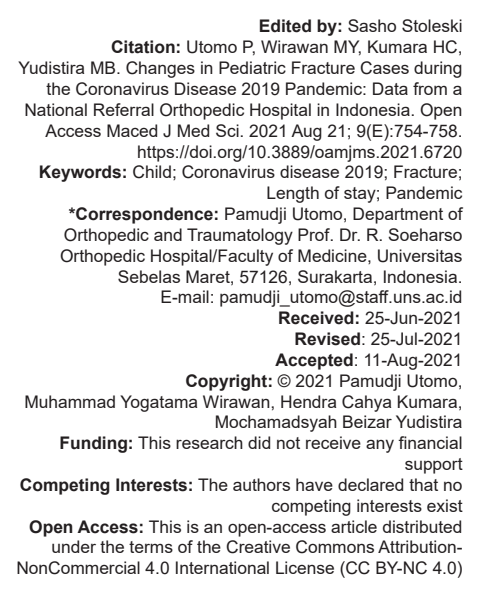

\begin{abstract}
AIM: This study aims to compare the impact of coronavirus disease 2019 (COVID-19) on pediatric fracture services in a national referral orthopedic hospital in Indonesia to understand the service provisions that may be required during the pandemic.

METHODS: The study compared the population group during 1 year of the COVID-19 pandemic in Indonesia to the same period 1 year before. This cross-sectional study was performed in Prof. Dr. R Soeharso Orthopedic Hospital, Surakarta, Indonesia, from March 2019 to February 2021. The subjects were pediatric fracture patients aged 0-18 years. Patients recorded on other orthopedic service support installations such as radiology, laboratory, or physiotherapy and diagnosed with any other orthopedic sub-specialty were excluded.

RESULTS: A total of 1787 patients were recorded in this study, with the mean of pediatric fracture patients during the pre-COVID-19 period was 90.75 (standard deviation [SD]: 28.5) and during the COVID-19 period was 58.16 (SD: 19.17) monthly. In the $1^{\text {st }}$ year of the pandemic, there was a significant reduction in clinical visits compared to the same period in 2019 ( $p<0.005)$

CONCLUSION: There were significant differences in pediatric fracture cases clinic visits and patients' length of stay in the COVID-19 period than before the COVID-19 occurred.
\end{abstract}

\section{Introduction}

Coronavirus disease 2019 (COVID-19) has been identified as the cause of an infectious respiratory disease outbreak in Wuhan, the People's Republic of China. The global pandemic of COVID-19 is still going on in over 200 countries. As of 24 March 2021, there were 123,902,242 confirmed cases worldwide. The number of deaths related to COVID-19 also reached $2,727,837$ worldwide. The pandemic has resulted in a rapid surge in research in response to condition [1].

By March 23, 2021, in Indonesia, there were 1,465,928 confirmed cases. The number of deaths related to COVID-19 also reached 39,711 in Indonesia1. Instead of a regional quarantine, Indonesia's president decided to enforce a large-scale social restriction/Pembatasan Sosial Berskala Besar (PSBB) in cities and provinces by March 2020. Only essential public services, such as grocery stores, gas stations, pharmacies, and hospitals, were allowed to remain open. Minister for Education and Culture of Indonesia, Nadiem Makarim, also stated that schools should be closed until the situation is under control. The government also emphasized the importance of all Indonesian people staying at home [2], [3].

Moreover, early data from Austria, Hong Kong, Italy, and California suggested a dramatic decline in the number of people seeking emergency medical services for other causes as the number of people diagnosed with COVID-19 escalated [4], [5], [6], [7]. In addition, hospital visits have been declining in many countries, including in emergency department [5], [8]. Furthermore, according to US centers, emergency department visits in the United States fell by more than half during the pandemic [7].

Early reports of COVID-19 in China centered on the adult population, with no reports of COVID19 in children [9]. However, as the infection spread around the world, more cases of infected children were reported [9], [10]. It is now known that children are not entirely safe, although, for unknown reasons, children are less susceptible to infection than adults [10]. 
On the other hand, public concerns about COVID-19, particularly among parents, are also feared to cause delays in child patient treatment. There is a report of a considerable reduction in child cases clinic visits in many countries. Official hospital statistics revealed significant decreases in pediatric emergency departments during Italy's national lockdown for COVID-19 [4]. Following the national lockdown for COVID-19, there has been a significant reduction in all trauma patients in New Zealand [11]. When the numbers were compared to the same period in previous years, a similar reduction in all pediatric fractures also occurred during school closures in the United States [12]. However, it remains unclear whether the pandemic has impacted the number of other pediatric fracture cases.

\section{Materials and Methods}

This research is a comparative cross-sectional analysis study. The study compared the pediatric fracture cases during the COVID-19 pandemic with those in the previous year. This study took place in a national referral orthopedic hospital, Prof. Dr. R. Soeharso Orthopedic Hospital Surakarta, Indonesia. The study was carried out from February 2021 until April 2021.

Data were collected from hospital digital medical records. First, anonymized records were gathered for 1 year from the $1^{\text {st }}$ month of the Indonesian government's statement about the first COVID-19 infection on its people (February 2020 - February 2021). Then, the data from 1 year before the COVID19 pandemic were used as a control (March 2019February 2020). Predefined characteristics: dates, age, sex, primary and secondary diagnosis, surgical therapy, etiology, supervisor, and installation were extracted. In addition, the nomenclature for diagnosis and therapy was based on ICD-10.

The inclusion criteria of this study were all patients who came to Prof. Dr. R. Soeharso Orthopedic Hospital with a pediatric fracture-related diagnosis from the emergency department, outpatient clinic, and inpatient. However, patients recorded on other orthopedic service support installations such as radiology, laboratory, or physiotherapy and diagnosed with any other orthopedic subspecialty were excluded.

Following ethics approval, the data were gathered from the medical records of Prof. Dr. R. Soeharso Orthopedic Hospital based on inclusion and exclusion criteria. The collected data were then classified based on the predefined characteristic aforementioned. The worksheet consisted of the study outcomes used to record the data monthly. Statistical analysis was employed to compare the data. In this case, different conditions before and during pandemics were compared. The difference between multiple time points (Months) during the pandemic was also calculated.

Statistical data were analyzed using an independent sample t-test or Mann-Whitney. The analyses were performed utilizing the Statistical Package for the Social Sciences (SPSS) for Windows version 26.0, manufactured by IBM in New York, USA. The difference between the number of outpatient visits between the two groups was considered statistically significant if $p<0.05$. The same method was used to analyze the differences in sex, ages, the number of different types of fracture, and the patient's length of stay.

\section{Results}

A total of 1787 patients were enrolled in this study. The mean of pediatric fracture patients during the pre-COVID-19 period was 90.75 (Standard Deviation [SD]: 28.5) patients, and during the COVID-19 period was 58.16 (SD 19.17) patients. Inpatient visits decreased significantly in the $1^{\text {st }}$ year of the pandemic compared to the same period in 2019 ( $p<0.005$ ). March 2020 had the lowest number of patient visits, which were only 22 visits. The monthly number of visits is shown in Figure 1.

The monthly number of patients according to their gender was also decreased. There were 43.3 (SD 15.3) boy patients per month in the COVID-19 period, compared to 63.6 (SD 22.3) per month 1 year before the COVID-19 period. There were 14.8 (SD 5.4) girl patients per month in the COVID-19 period, compared to 27 (SD 9.8) per month 1 year before the COVID-19 period. The monthly number of patients related to sex is displayed in Figures 2 and 3.

A decrease in several fracture locations and age groups was recorded in the 1 year of the pandemic period compared to the previous period, as shown in Tables 1 and 2. The researchers also analyzed the impact of COVID-19 on the patient's length of stay. Again, the researchers found a significant decrease $(p<0.05)$, shown in Figure 4.

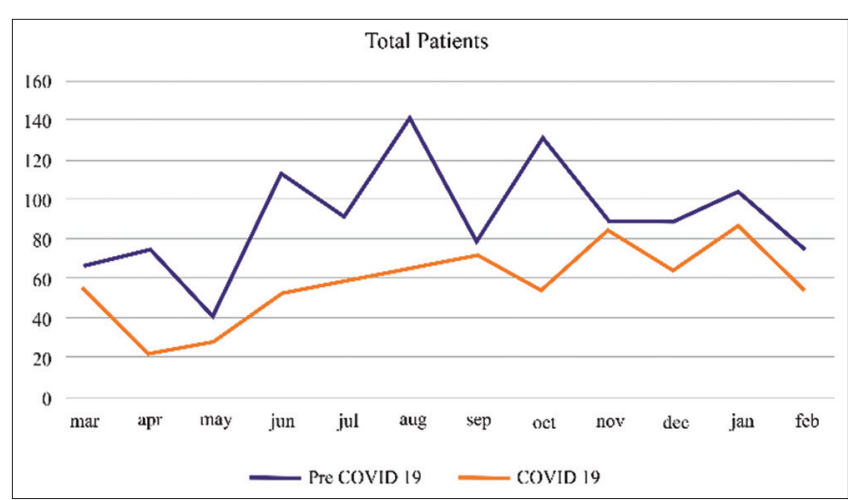

Figure 1: Total pediatric orthopedic patients 


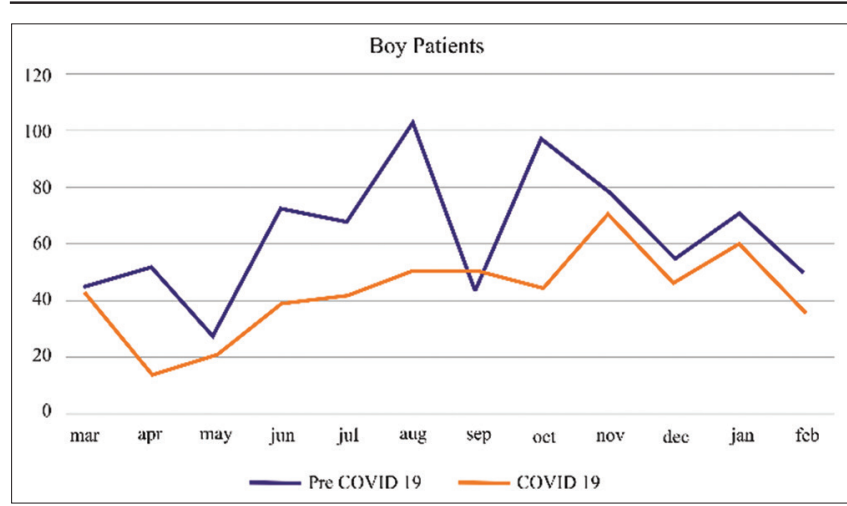

Figure 2: Total boy patients

\section{Discussion}

The findings of this study indicate that the total patients decreased significantly in each month during COVID-19 compared to the total patients during the comparison period $(p<0.05)$. In addition, the data revealed that the number of pediatric fracture cases decreased significantly in April, with only 22 cases reported.

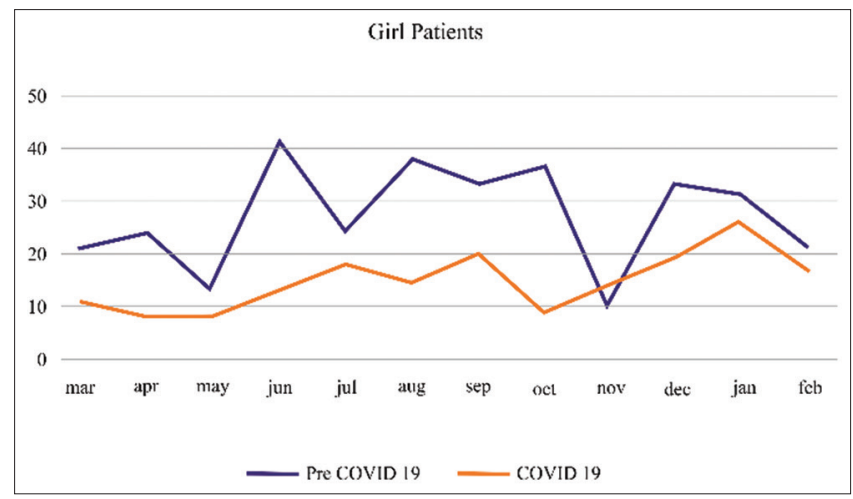

Figure 3: Total girl patients

These results might happen because of activity limitations, including school closure, preventing trauma events in children. These findings support the previous research that found a significant decline in inpatient visits in Austria since the pandemic [5]. Another report backs up these research findings, stating that the number of visits to the emergency department in Hong Kong decreased significantly compared to the same period in the previous year, including emergency and life-threatening cases like acute coronary syndrome [6]. Another research uncovered a significant decrease in the number of visits to pediatric emergency departments, including in cases of acute illness and trauma, supporting the current study results. The number of people needing emergency care services has decreased significantly in many countries. These considerations and the parents' worry of infecting their children by going to the hospital should all be taken into account [4]. When the numbers were compared to the same period in the previous year, a similar reduction in all pediatric fractures also occurred during school closures in the United States [12]. When the Indonesian limitation activity policy, known as PSBB, began on

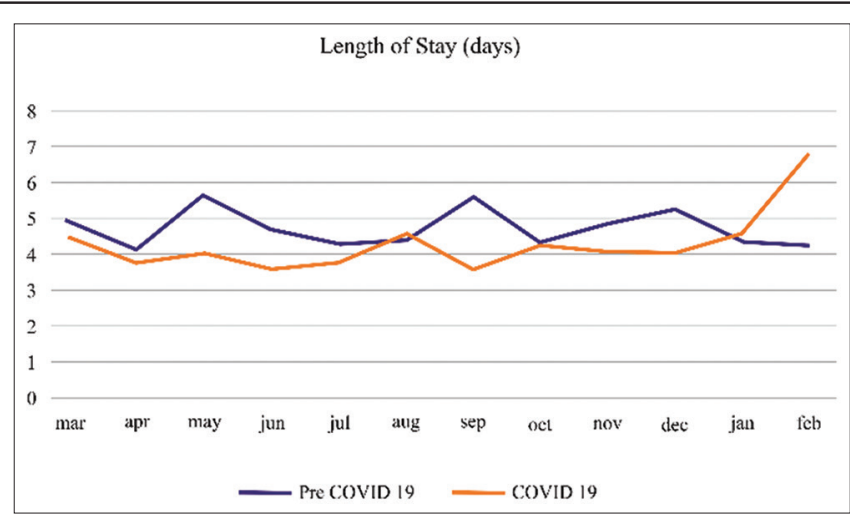

Figure 4: Length of stay

March 31, 2020, the total number of patients dropped dramatically a month later [3].

Table 1: Location of fracture (*significant)

\begin{tabular}{llll}
\hline Location of pediatric fracture & \multicolumn{3}{l}{ Mean number of patients monthly } \\
\cline { 2 - 4 } & Pre-COVID & COVID-19 & p-value \\
& $19($ SD $)$ & (SD) & \\
\hline Fracture of lumbar spine and pelvis & $2.41(1.37)$ & $1.41(1.08)$ & $0.078^{*}$ \\
Fracture shoulder and upper arm & $25.17(8.06)$ & $16.5(6.31)$ & $0.008^{*}$ \\
Fracture of forearm & $30(11.26)$ & $19.5(8.71)$ & $0.018^{*}$ \\
Fracture at wrist and hand level & $6.08(2.19)$ & $3.25(2.52)$ & $0.008^{*}$ \\
Fracture of femur & $14.41(7.05)$ & $9.25(4.09)$ & $0.039^{*}$ \\
Fracture of the lower leg, including ankle & $12.67(6.45)$ & $8.25(5.42)$ & 0.083 \\
\hline
\end{tabular}

The general trend was the same in the COVID-19 and pre-COVID-19 periods. However, the difference in the number of fractures in boys and girls has narrowed significantly in the COVID-19 period. It could be partly due to the floor effect. The total number of cases has decreased in both sexes, but the prevalence of cases in certain age girl groups was so low that they could not decline as much as boys. Furthermore, in the pre-COVID-19 period, boys were likely more involved with lockdown activities than girls [13], [14], so the effect of lockdown was more significant in boys.

Further, there was a decrease in all age groups in pediatric fracture cases. There was a significant reduction in the 11-15 years and 16-18 years age groups. These results are similar to the study that stated a significant decrease in pediatric fracture admission [15], [16]. Whereas, in the age group 0-5 years and 5-10 years, the decrease was not significant. In contrast to similar studies, there was a significant decrease in emergency cases, which was relatively high in the 0-14 years old group [8], [17], [18].

Thus, it is necessary to consider the differences in activity limitation policies in each country. The studies mentioned above were conducted in countries with stricter quarantine or lockdown policies than Indonesia. Because of the effectiveness of each policy, the outcomes may differ. The people's habit of

Table 2: Age group (*significant)

\begin{tabular}{llll}
\hline Age group & \multicolumn{4}{l}{ Mean number of patients monthly } \\
\cline { 2 - 4 } & Pre-COVID 19 (SD) & COVID-19 (SD) & p-value \\
\hline 0-5 years & $15.08(6.38)$ & $12.25(2.76)$ & 0.173 \\
6-10 years & $23.41(11.7)$ & $16.41(8.02)$ & 0.125 \\
$11-15$ years & $31.08(11.6)$ & $18.41(6.5)$ & $0.003^{*}$ \\
$16-18$ years & $21.16(9.97)$ & $11.08(5.58)$ & $0.004^{*}$ \\
\hline
\end{tabular}


using traditional medicine also needs to be considered a factor influencing this study's findings.

For both before and during the COVID-19 pandemic, the most common fracture locations were the forearm, shoulder and upper arm, and femur fractures. In the shoulder, upper arm, forearm, wrist, hand, and femur groups, there was a significant reduction in cases. These results are in line with a study that showed a considerable difference in the number of outpatient visits and orthopedic surgery procedures during the beginnings of the pandemic relative to the time before the outbreak [19], [20], [21], [22], [23]. In contrast, the decrease was not significant in the lumbar spine, pelvis, lower leg, and ankle. It differs from a report disclosing that patients diagnosed with vertebral fractures during the COVID19 pandemic were significantly reduced [16]. It could happen because the characteristics of the subject studied were different.

COVID-19 pandemics have caused substantial disruptions to orthopedic and trauma services with more pronounced reductions in elective surgery [24]. Early data from Indonesia revealed dramatic declines in the number of surgery loads in March, April, and May 2020 [19]. Pediatric orthopedic practice has also been seriously affected, as the number of elective surgeries and outpatient clinics have had to be reduced [18]. We hypothesized that the volume of elective pediatric orthopedic surgery in Indonesia would also decrease. However, there has been no research on changes in the number of elective pediatric orthopedics surgeries in Indonesia. Further research is needed about this matter.

Furthermore, there was a significant reduction in the patient's length of stay. Along with the WHO interim guidance, this finding indicates that inpatient admission processes may need to be adjusted as the risks and benefits of hospital-based care change suggest that inpatient admission processes may need to be modified [25]. Other studies from many countries also uncovered a decrease in patient's length of stay due to pandemic [26], [27]. Discharge planning coordinated with primary care follow-up can also help to shorten hospital stays.

\section{Conclusion}

There were significant differences in total pediatric fracture cases clinic visits and patients' length of stay in the COVID-19 period than before the COVID19 occurred. Further research is needed to identify the efficacy of PSBB compared to other nations' activity limitation policies since several categories show insignificant changes before and during the COVID-19 period.

\section{Author Contribution}

Pamudji Utomo, Muhammad Yogatama Wirawan, Hendra Cahya Kumara, and Mochamadsyah Beizar Yudistira contribute the same and equally in conceptualization, collecting the data, analyzing, writing, and reviewing the manuscript to report this case series.

\section{Acknowledgment}

The researchers thank Prof. Dr. R. Soeharso Hospital and the patients who have allowed the researchers to collect data and publish this manuscript.

\section{References}

1. World Health Organization. WHO Coronavirus (COVID-19) Dashboard, WHO Coronavirus Disease (COVID-19) Dashboard; 2021. Available from: https://www.covid19.who.int. https://doi. org/10.46945/bpj.10.1.03.01. [Last accessed on $2021 \mathrm{Apr} 20$ ].

2. Setiati S, Azwar MK. COVID-19 and Indonesia. Acta Med Indones. 2020;52(1):84-9.

PMid:32291377

3. Central Government of Republic of Indonesia. Tahun 2020 Tentang Pembatasan Sosial Berskala Besar dalam Rangka Percepatan Penanganan Corona Virus Disease 2019 (COVID-19) [JDIH BPK RI].; 2020. Available from: https:// www.peraturan.bpk.go.id/Home/Details/135059/pp-no-21tahun-2020. [Last accessed on 2021 Apr 22]. https://doi. org/10.26858/supremasi.v15i2.13959

4. Lazzerini M, Barbi E, ApicellaA, Marchetti F, Cardinale F, Trobia G. Delayed access or provision of care in Italy resulting from fear of COVID-19. Lancet Child Adolesc Health. 2020;4(5):e10-1. https://doi.org/10.1016/s2352-4642(20)30108-5 PMid:32278365

5. Metzler B, Siostrzonek P, Binder RK, Bauer A, Reinstadler SJ. Decline of acute coronary syndrome admissions in Austria since the outbreak of COVID-19: The pandemic response causes cardiac collateral damage. Eur Heart J. 2020;41(19):1852-3. https://doi.org/10.1093/eurheartj/ehaa314 PMid:32297932

6. Tam CC, Cheung KS, Lam S, Wong A, Yung A, Sze M, et al Impact of coronavirus disease 2019 (COVID-19) outbreak on ST-segment-elevation myocardial infarction care in Hong Kong, China. Circ Cardiovasc Qual Outcomes. 2020;2019:6734. https://doi.org/10.1161/circoutcomes.120.006734

7. Wong LE, Hawkins JE, Langness $S$, Murrell KL, Iris $P$, Sammann A. Where are all the patients? addressing covid19 fear to encourage sick patients to seek emergency care. NEJM Catal. 2020;2020:1-12. https://catalyst.nejm.org/doi/ abs/10.1056/CAT.20.0193

8. Hartnett, Kathleen P, Kite-Powell A, DeVies J, Coletta MA Boehmer TK, Adjemian J, et al. Impact of the COVID-19 pandemic on emergency department visits-United States, January 1, 2019-May 30, 2020. MMWR Morb Mortal Wkly 
Rep. 2020;69(23):699-704. https://doi.org/10.15585/mmwr. $\mathrm{mm} 6923 \mathrm{e} 1$

PMid:32525856

9. Gao Q, Hu Y, Dai Z, Xiao F, Wang J, Wu J. The epidemiological characteristics of 2019 novel coronavirus diseases (COVID-19) in Jingmen, Hubei, China. MedRxiv. 2020;2020:20605. https:// doi.org/10.1097/md.0000000000020605

10. Bialek S, Gierke R, Hughes M, McNamara LA, Pilishvili T, Skoff T. Coronavirus disease 2019 in children: Current statusMorbidity and Mortality Weekly Report. 2020;69(14):422-6. https://doi.org/10.15585/mmwr.mm6914e4

11. Christey G, Amey J, Campbell A, Smith A. Variation in volumes and characteristics of trauma patients admitted to a level one trauma centre during national level 4 lockdown for COVID-19 in New Zealand. N Z Med J. 2020;133(1513):81-8.

PMid:32325471

12. Bram JT, Johnson MA, Magee LC, Mehta NN, Fazal FZ, Baldwin $\mathrm{KD}$, et al. Where have all the fractures gone? The epidemiology of pediatric fractures during the COVID-19 pandemic. J Pediatr Orthop. 2020;40(8):373-9. https://doi. org/10.1097/bpo.0000000000001600

PMid:32433260

13. Tandon T, Shaik M, Modi N. Paediatric trauma epidemiology in an urban scenario in India. J Orthop Surg (Hong Kong) 2007;15(1):41-5. https://doi.org/10.1177/230949900701500110 PMid:17429116

14. Rennie L, Court-Brown CM, Mok JY, Beattie TF. The epidemiology of fractures in children. Injury. 2007;38(8):913-22. https://doi.org/10.1016/j.injury.2007.01.036 PMid:17628559

15. Sheridan GA, Nagle M, Russell S, Varghese S, O'Loughlin PF, Boran $S$, et al. Pediatric trauma and the COVID-19 pandemic: A 12-year comparison in a level-1 trauma center. HSS J. 2020;16(1):92-6. https://doi.org/10.1007/s11420-020-09807-y PMid:33041725

16. Skryabin EG, Akselrov MA, Zotov PB. Vertebral fractures in children. Ecovector J. 2020;8:373-82.

17. Raitio $A$, Ahonen $M$, Jääskelä $M$, Jalkanen J, Luoto TT, Haara M, et al. Reduced number of pediatric orthopedic trauma requiring operative treatment during COVID-19 restrictions: A nationwide cohort study. Scand J Surg. 2020;110(2):254-257. https://doi. org/10.1177/1457496920968014

PMid:33100133

18. Ertan Birsel S, Sarıkaya IA, Şeker A, Erdal OA, Görgün B, İnan M. How the COVID-19 pandemic is affecting paediatric orthopaedic practice in Turkey. J Child Orthop. 2020;14(6):581-8. https://doi. org/10.1302/1863-2548.14.200174

\section{PMid:33343754}

19. Rhatomy S, Phatama KY, Rasyid FA, Mustamsir E. Changes in orthopedic services in two indonesian tertiary-referral hospitals during the coronavirus-19 pandemic. Open Access Maced J Med Sci. 2020;8(1):538-41. https://doi.org/10.3889/ oamjms.2020.5491

20. Umeda-Raffa S, Pergolizzi JV, Raffa RB. Bone fractures during the time of coronavirus. J Clin Pharm Ther. 2021;46(2):543-6. https://doi.org/10.1111/jcpt.13297

PMid:33104253

21. MacDonald DR, Neilly DW, Davies PS, Crome CR, Jamal B, Gill SL, et al. Effects of the COVID-19 lockdown on orthopaedic trauma: A multicentre study across Scotland. Bone Jt Open. 2020;1(9):541-8. https://doi.org/10.1302/2633-1462.19.bjo2020-0114.r1 PMid:33215152

22. Ribau A, Vale J, Xará-Leite F, Rodrigues-Pinto R. Impact of COVID-19 pandemic and national lockdown in an orthopaedic and traumatology department-a comparison with the homologous period of 2019. Porto Biomed J. 2021;6(1):e109. https://doi.org/10.1097/j.pbj.0000000000000109 PMid:33490702

23. Murphy T, Akehurst H, Mutimer J. Impact of the 2020 COVID-19 pandemic on the workload of the orthopaedic service in a busy UK district general hospital. Injury. 2020;51(10):2142-7. https:// doi.org/10.1016/j.injury.2020.07.001 PMid:32654849

24. Wong JS, Cheung KM. Impact of COVID-19 on Orthopaedic and Trauma Service: An Epidemiological Study. J Bone Jt Surg Am. 2020;102(14):E80. https://doi.org/10.2106/jbjs.20.00775 PMid:32675668

25. World Health Organization. Maintaining Essential Health Services: Operational Guidance for the COVID-19 Context Interim Guidance; 2020. Available form: https://www.who. int/publications/i/item/WHO-2019-nCoV-essential-healthservices-2020.1. [Last accessed on 2021 Apr 11].

26. Turgut A, Arlı H, Altundağ Ü, Hancıoğlu S, Egeli E, Kalenderer Ö. Effect of COVID-19 pandemic on the fracture demographics: Data from a tertiary care hospital in Turkey. Acta Orthop Traumatol Turc. 2020;54(4):355-63. https://doi.org/10.5152/j. aott.2020.20209

PMid:32812872

27. Atia F, Pocnetz S, Selby A, Russell P, Bainbridge C, Johnson N The effect of the COVID-19 lockdown on hand trauma surgery utilization. Bone Jt Open. 2020;1(10):639-43. https://doi. org/10.1302/2633-1462.110.bjo-2020-0133.r1

PMid:33215095 